\title{
IDENTIFICATION OF CANINE VISCERAL LEISHMANIASIS IN A PREVIOUSLY UNAFFECTED AREA BY CONVENTIONAL DIAGNOSTIC TECHNIQUES AND CELL-BLOCK FIXATION
}

Tuanne Rotti AbranteS(1), Maria de Fátima MADEIRA(2), Denise Amaro da SILVA(1), Carolina dos Santos F. S. PERIÉ(3), Artur Augusto V. MENDES JÚNIOR(4), Rodrigo Caldas MENEZES(4), Valmir Laurentino SILVA(5) \& Fabiano Borges FIGUEIREDO(4)

\begin{abstract}
SUMMARY
After the report of a second case of canine visceral leishmaniasis (CVL) in São Bento da Lagoa, Itaipuaçu, in the municipality of Maricá, Rio de Janeiro State, an epidemiological survey was carried out, through active search, totaling 145 dogs. Indirect immunofluorescence assay (IFA), enzyme-linked immunosorbent assay (ELISA), and rapid chromatographic immunoassay based on dual-path platform (DPP®) were used to perform the serological examinations. The parasitological diagnosis of cutaneous fragments was performed by parasitological culture, histopathology, and immunohistochemistry. In the serological assessment, 21 dogs were seropositive by IFA, 17 by ELISA, and 11 by DPP®, with sensitivity of $66.7 \%, 66.7 \%$ and 50\%, and specificity of $87.2 \%, 90.2 \%$ and $94 \%$, respectively for each technique. The immunohistochemistry of bone marrow using the cell-block technique presented the best results, with six positive dogs found, three of which tested negative by the other parasitological techniques. Leishmania sp. was isolated by parasitological culture in three dogs. The detection of autochthonous Leishmania infantum in Itaipuaçu, and the high prevalence of seropositive dogs confirm the circulation of this parasite in the study area and alert for the risk of expansion in the State of Rio de Janeiro.
\end{abstract}

KEYWORDS: Canine visceral leishmaniasis; Dogs; Diagnosis; Cell-block.

\section{INTRODUCTION}

American visceral leishmaniasis is a zoonosis that affects humans and other species of domestic and wild animals. It is caused by the protozoan Leishmania infantum, whose main vector is the dipteran Lutzomyia longipalpis ${ }^{1}$.

In Brazil, canine visceral leishmaniasis (CVL) is still expanding ${ }^{1,2,3,4}$. For the diagnosis among dogs, it is necessary to evaluate tools that can safely discriminate infected animals $\mathrm{s}^{5,6,7,8,9,10}$.

In endemic CVL areas, serological tests are used in epidemiological surveys for the diagnosis and subsequent euthanasia of seropositive dogs ${ }^{1}$. These tests are considered sensitive and specific; however, they have limitations to detect low levels of antibodies and present cross-reactivity with canine tegumentary leishmaniasis ${ }^{11}$.

Regarding CVL, the distribution of the parasite can be extensive, reaching organs such as the spleen, liver, lymph nodes, skin, and bone marrow $^{12}$. Direct microscopic identification and isolation of the parasite in culture from different clinical specimens are among the parasitological methods used ${ }^{1}$. Parasitological culture is considered the reference standard for the diagnosis of leishmaniasis ${ }^{13}$ and allows the identification of species by multilocus enzyme electrophoresis. Histopathological (HP) and immunohistochemical (IHC) analyses are also used for direct microscopic identification of amastigotes of Leishmania. IHC is more sensitive compared to $\mathrm{HP}^{14}$.

Cell-block preparation is a technique used in human medicine $\mathrm{e}^{7,15,16}$. It consists of the concentration of cells by centrifugation or filtration. The cell block is formed as a processed tissue sample, allowing analysis by histopathology and immunohistochemistry, preserving the cell morphology ${ }^{7}$.

Increased rates of canine seroprevalence have been observed in the state of Rio de Janeiro in recent years ${ }^{17}$. The first autochthonous case of CVL was reported in Inoã in the municipality of Maricá, in 2009; since then, new cases have been described in nearby regions. After the notification of the first autochthonous case of CVL in Maricá, Rio de Janeiro State ${ }^{18}$, we started a canine epidemiological survey using several conventional diagnostic methods and a new technique, immunohistochemistry through the use of cell-block fixation for the diagnosis of infection by Leishmania infantum.

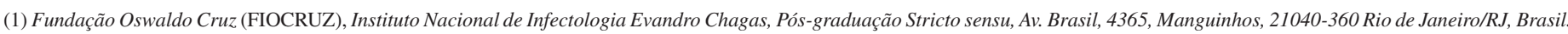

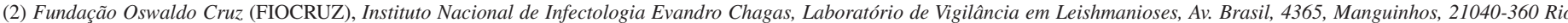
de Janeiro/RJ, Brasil.

(3) Veterinária autônoma.

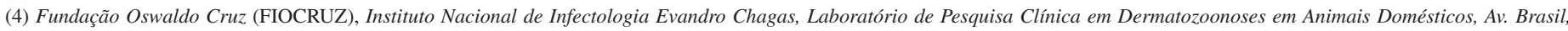
4365, Manguinhos, 21040-360 Rio de Janeiro/RJ, Brasil.

(5) Fundação Oswaldo Cruz (FIOCRUZ), Escola Nacional de Saúde Pública, Laboratório de Imunodiagnóstico, Av. Brasil, 4365, Manguinhos, 21040-360 Rio de Janeiro/RJ, Brasil.

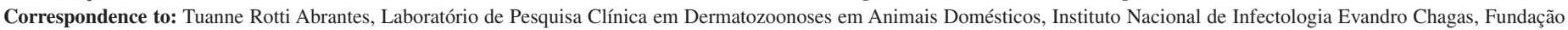
Oswaldo Cruz (FIOCRUZ). Av. Brasil, 4365 Manguinhos 21040-360 Rio de Janeiro, RJ, Brasil.. Phones: + 55 (21) 38659536. + 55 (21)38659553. E-mail: tuanne_rotti@ yahoo.com.br 


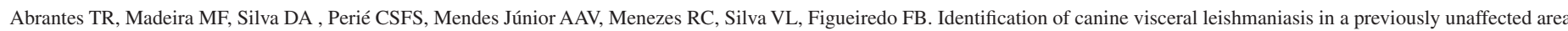
by conventional diagnostic techniques and cell-block fixation. Rev Inst Med Trop Sao Paulo. 2016;58:3.

\section{MATERIALS AND METHODS}

Study design: A sectional study with a convenience sample of 145 dogs was carried out in São Bento da Lagoa, Itaipuaçu, municipality of Maricá, Rio de Janeiro State, between 2009 and 2011. Dogs aged eight months or older, and living in the area for more than two years without a history of travelling, were included in the study, providing that their owners agreed to participate. Animals that did not present good general health or conditions for sedation, pregnant female dogs, aggressive dogs, stray dogs, or those that had undergone any anti-Leishmania chemotherapy were excluded from the study. The procedures used in this animal research were approved by the Ethics Committee on Animal Use (CEUA- FIOCRUZ), under license No. LW-43/10.

Clinical assessment and samples collection: The dogs were sedated with ketamine $(10 \mathrm{mg} / \mathrm{kg})$ associated with acepromazine maleate $(0.2$ $\mathrm{mg} / \mathrm{kg}$ ) and subjected to physical examination, collection of blood, bone marrow puncture, biopsy of healthy skin from the scapular region, and biopsy of the cutaneous lesion. The serological tests were conducted using the following kits: indirect immunofluorescence assay (IFA), enzymelinked immunosorbent assay (ELISA), and rapid chromatographic immunoassay based on dual-path platform (DPP®) (Bio-Manguinhos/ FIOCRUZ - Rio de Janeiro, Brazil). The manufacturer's recommendations contained in the kit label were followed for all serological techniques.

The following procedures were carried out to collect skin biopsy fragments: trichotomy with disposable stainless steel razorblades, antisepsis, and local anesthesia with lidocaine $2 \%$ without vasoconstrictor. Four fragments of healthy skin of the scapular region of each animal were collected using a $3 \mathrm{~mm}$ punch for parasitological examination. Two fragments were stored in sterile saline solution, complete with antifungal and antibiotic, for further processing in culture, and two fragments were fixed in $10 \%$ neutral buffered formalin for the HP and IHC analyses. When cutaneous lesions were found, two fragments were also collected for parasitological examination.

Fragments of tissue (skin and lesion), fixed in 10\% neutral buffered formalin were processed for paraffin embedment. In the HP, sections of $5 \mu \mathrm{m}$ thickness were cut and stained with hematoxylin and eosin (HE). In the IHC, the procedures were conducted following the protocol of QUINTELA et al. ${ }^{14}$.

The bone marrow aspirate was obtained from the manubrium of the sternum using a $20 \mathrm{~mL}$ syringe with a 40 x $12 \mathrm{~mm}$ needle, after trichotomy, antisepsis, and local anesthesia with lidocaine $2 \%$. Approximately $0.1-0.2 \mathrm{~mL}$ of the sample obtained in the aspiration was placed in a tube containing biphase culture medium Novy, MacNeal, Nicole (NNN) and Schneider's insect medium supplemented with $10 \%$ fetal bovine serum for isolation of Leishmania. The remaining material, approximately $0.5 \mathrm{~mL}$, was placed in a sterile tube containing EDTA, centrifuged at $3000 \mathrm{rpm}$ for $10 \mathrm{~min}$, with separation of leukocytes and erythrocytes, followed by discarding of the supernatant, and addition of the cell-block fixative $(850 \mathrm{~mL}$ absolute alcohol, $100 \mathrm{~mL}$ of formalin, and $50 \mathrm{~mL}$ of acetic acid) to the sediment. The resulting block of cells was processed to conduct the immunohistochemistry, following the protocol of QUINTELA et al. (2009) ${ }^{14}$. The parasites isolated in culture were identified by the technique of isoenzymes, using the protocol described by CUPOLILLO et al. $^{19}$.
After clinical and laboratorial evaluation, the dogs were classified as exposed, infected, ill and severely ill, in an adaptation of the protocol by PALTRINIERI et al. ${ }^{20}$.

Traps: An entomological study was performed in the area in order to verify the presence of phlebotomine sandflies. For this purpose, we conducted captures using the CDC Light Traps ${ }^{21}$. After collecting the samples from the animals, the traps were set a meter from the ground in places that had already been referred to as places presenting with higher incidence of phlebotomine sandflies, such as fowl runs and banana trees. On average, two traps were set in the peridomicile around different dwelling per working day. The traps were placed at 6 p.m. and collected in the next morning at 8 a.m., totaling 14 hours of capture/trap ${ }^{22}$. The adults were collected alive and transferred to plastic containers labeled and identified in accordance with the collection points. After being transported to the laboratory, the adult sandflies were killed by freezing in a freezer at $-20{ }^{\circ} \mathrm{C}$, and subjected to taxonomic identification at the species level, according to GALATI ${ }^{23}$.

Statistical analysis: The software program Statistical Package for the Social Science (SPSS), version 16.0, was used to describe the frequencies of results for clinical evaluation, sensitivity, specificity, false positive, and false negative; the parasitological techniques (culture, HP, IHC and IHC with cell-block fixation) were used as reference standard. A dog was considered infected with Leishmania infantum when it presented positive diagnosis in at least one of the parasitological techniques employed.

\section{RESULTS}

During the study period (2009-2011), 145 dogs (54.5\% female) were assessed. All dogs which were positive in either serological or parasitological methods were born in the area without history of traveling. Only two dogs showed clinical signs consistent with CVL. Both of them presented regional adenitis, peeling, weight loss, and ophthalmic alteration (keratoconjunctivitis), in addition to positive diagnosis in all tests employed. One of them also had a lesion in the ear pinna. The other infected dogs showed no signs consistent with the disease.

The serological techniques showed a seroprevalence of $25.2 \%$. Table 1 presents the frequency, sensitivity, and specificity of each technique.

Table 2 shows the seven animals with positive parasitological diagnosis and their respective serological results. Leishmania infantum was isolated in culture of healthy skin of three animals.

Thirteen dogs were false positive by ELISA, 17 by IFA, and 8 by $\mathrm{DPP} \circledast$; and two dogs were falsenegative by ELISA and IFA, and three by $D P P \circledR$.

According to the classification of PALTRINIERI et al. ${ }^{20}, 139 \mathrm{dogs}$ were considered exposed (95.9\%), six dogs were infected $(4.1 \%)$, and two $(1.3 \%)$ were ill; no animals were considered severely ill.

No phlebotomine sandflies were found during the period of capture.

\section{DISCUSSION}

The occurrence of new cases of canine visceral leishmaniasis has 


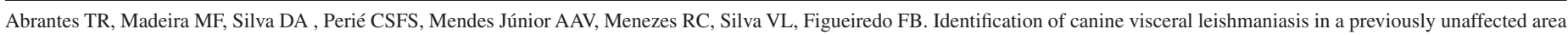
by conventional diagnostic techniques and cell-block fixation. Rev Inst Med Trop Sao Paulo. 2016;58:3.

Table 1

The frequency, sensitivity and specificity of serological techniques

\begin{tabular}{lccc}
\hline Test & Frequency & Sensitivity & Specificity \\
\hline IFA & $21(0,135)$ & $66.7 \%($ IC $95 \%: 30-90.3 \%)$ & $87.2 \%($ IC $95 \%: 80.4-90.8 \%)$ \\
ELISA & $17(0,109)$ & $66.7 \%($ IC $95 \%: 30-90.3 \%)$ & $90.2 \%($ IC $95 \%: 83.9-94.2 \%)$ \\
DPP & $11(0,070)$ & $50 \%($ IC $95 \%: 18.7-81.2 \%)$ & $94 \%($ IC $95 \%: 88.5-96.9 \%)$ \\
\hline
\end{tabular}

Table 2

The seven animals with positive parasitological diagnosis and their respective serological results

\begin{tabular}{lcccccccc}
\hline \multirow{2}{*}{ Animals } & Culture of skin & IHC of skin & HP of skin & $\begin{array}{c}\text { Culture of bone } \\
\text { marrow }\end{array}$ & Cell-block & IFA & ELISA & DPP® \\
\hline $1^{*}$ & Positive & Positive & Positive & Positive & Positive & Positive & Positive & Positive \\
2 & Positive & Positive & Positive & Positive & Positive & Positive & Positive & Positive \\
3 & Negative & Positive & Negative & Negative & Positive & Positive & Negative & Negative \\
4 & Negative & Negative & Negative & Negative & Positive & Positive & Positive & Positive \\
5 & Negative & Negative & Negative & Negative & Positive & Negative & Positive & Negative \\
7 & Negative & Negative & Negative & Negative & Positive & Negative & Negative & Negative \\
7 & Positive & Positive & Negative & Negative & Negative & Positive & Negative & Negative \\
\hline
\end{tabular}

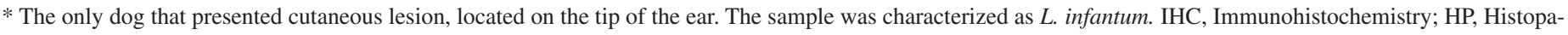
thology; DPP, Dual-Path Platform technology; ELISA, Enzyme Linked Immunosorbent Assay; IFA, Indirect Immunofluorescence Assay

been reported in several regions of the municipality surveyed and in the State of Rio de Janeiro, which indicates a possible change in behavior of this endemic disease, enabling the emergence of an outbreak in urban areas, as it has already occurred in other Brazilian cities ${ }^{1,24}$. Because urbanization of the disease is a relatively new phenomenon, little is known about the epidemiology of VL in urban foci. Over the past few years, the municipality of Maricá has been experiencing migration of humans with their pets, associated with environmental changes and mainly with leisure activities. Such activity has already been associated with cases of tegumentary leishmaniasis described in this municipality ${ }^{25}$.

In the present study, we aimed to carry out a canine survey in the neighborhood of São Bento da Lagoa, Itaipuaçu, municipality of Maricá a new area with occurrence of CVL.

We compared the serological techniques recommended by the Brazilian Ministry of Health until 2011 (screening with ELISA and confirmation with IFA), and after 2012 (screening with DPP® and confirmation with ELISA) ${ }^{24}$.

Cell-block immunohistochemistry on bone marrow samples was the method that showed the best results compared with other parasitological examinations; it can be considered a good technique for the diagnosis of CVL, facilitating the detection of positive animals, encompassing a larger number of affected dogs in a region. In this technique, cells were centrifuged and leukocytes were separated from erythrocytes, and a layer of leukocytes infected with amastigotes of Leishmania infantum was formed ${ }^{26}$, enabling easier detection by antigen-antibody reaction.

The IHC and parasitological culture of skin samples demonstrated better results compared to the HP in the same site of capture. Although $\mathrm{HP}$ is an important diagnostic method of CVL, because it can identify the parasitic forms and simultaneously contribute to the differential diagnosis, it presents low sensitivity and can often be inconclusive ${ }^{27}$.

The IFA showed the highest seroprevalence (14.5\%), followed by ELISA (11.7\%), and DPP® (7.6\%). The IFA showed sensitivity rates similar to that of ELISA (66.7\%), and higher than that of DPP® $(50 \%)$.

Studies have demonstrated problems regarding the IFA when compared with ELISA in the diagnosis of CVL, such as low specificity and sensitivity, consequently producing false positive and falsenegative results. The high number of seropositive dogs found in the study by IFA shows the low specificity of this technique, as well as a larger number of falsepositive and falsenegative dogs compared with other serological techniques, corroborating the results described in the literature ${ }^{6,28}$.

GRIMALDI et $a l .{ }^{5}$ reported that DPP ${ }^{\circledR}$ showed lower sensitivity when the evaluated group comprised asymptomatic dogs. Our study corroborates these results, with only two infected dogs presenting signs consistent with CVL, which can justify the low sensitivity of this test. However, SILVA et al. ${ }^{9}$ obtained good results with DPP®, similar to ELISA, with antigens of Leishmania infantum. The disagreement between these results may be related to the methodology of animal selection, considering that in our study and in the study by GRIMALDI et al. ${ }^{5}$, the samples were collected in the field, while in the study by SILVA et al. ${ }^{9}$ the animals were from a serological survey for CVL control, where they were selected, therefore increasing the bias in the study.

The majority (98.6\%) of the animals in this study presented no clinical 


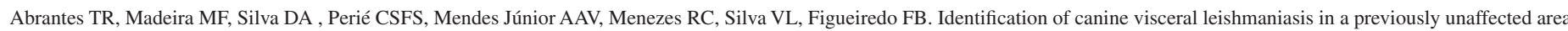
by conventional diagnostic techniques and cell-block fixation. Rev Inst Med Trop Sao Paulo. 2016;58:3.

signs consistent with CVL. The two animals showing clinical signs were positive in all the diagnostic techniques employed. It is believed that approximately 40 to $60 \%$ of the seropositive canine population is asymptomatic ${ }^{30}$, which hinders the diagnosis of the disease and demonstrates the need for laboratory confirmation.

Until 2011, the Brazilian Ministry of Health recommended the removal and euthanasia of dogs that presented positive parasitological diagnosis or were seropositive by IFA with dilutions of 1:40 or greater ${ }^{1}$, aiming to interrupt the transmission cycle. By the previous criterion (ELISA and IFA) used by the Brazilian Ministry of Health, confirming the reference standard established in our study, three non-infected dogs would be euthanized and two infected dogs would remain in the area; while using the new criterion (DPP $®$ and ELISA), one non-infected dog would be removed and three infected dogs would remain in the area. In our study, DPP showed low sensitivity, promoting the permanence of infected dogs in the study area. This result can be explained by the low number of animals showing clinical signs, agreeing with the results presented by GRIMALDI et al. ${ }^{5}$. Another factor that may have influenced DPP® sensitivity assessment was the number of dogs in the study sample, which was not representative for validation.

Euthanasia is a measure of control that generates much discussion due to lack of consensus among researchers as to the accuracy of the tests currently used in surveys $\mathrm{s}^{8,12,29,31}$. SILVA et al. ${ }^{10}$ evaluated 155 seropositive animals with titters above 1:40 in the IFA performed by filter paper absorbed blood eluate; these animals were removed and euthanized by the leishmaniasis control program of the city of Rio de Janeiro. Of the 155 dogs assessed, only 14 presented the isolation of Leishmania infantum and 17 animals were positive in samples of healthy skin by polymerase chain reaction (PCR). Ninety-one (59\%) animals were negative in all tests in the study, indicating that these animals were removed and euthanized without being infected with Leishmania infantum or any other agent. The results found in this study and others encouraged the withdrawal of IFA as a screening test, being replaced by DPP®, and ELISA becoming the new confirmatory test.

The animals with positive parasitological diagnosis were removed and euthanized, while the seropositive dogs were notified to the municipality of Maricá and the Secretary of Health of the State of Rio de Janeiro.

Although no phlebotomine sandfly has been found, we cannot say that the vector was not present because the capture of sandflies may be influenced by environmental factors and the period of capture may have been insufficient in our study. On the other hand, some authors suggest other possible transmission forms, such as venereal, vertical ${ }^{32}$, and by tick $^{33}$; however, venereal transmission and transmission by ticks are not yet proven.

The present study describes a canine epidemiological survey in an area that was not considered endemic for CVL, confirming the circulation of Leishmania infantum in the region. Furthermore, the application of the technique of cell-block fixation was indicated as a new alternative tool for the diagnosis of CVL.

\section{ACKNOWLEDGMENTS}

This study was supported by Fundação de Amparo à Pesquisa do
Estado do Rio de Janeiro (FAPERJ) (Grants: JCNE E-26/103.223/2011 and EDNR E-26/110.598/2012). Fabiano Borges Figueiredo holds a grant from Conselho Nacional de Pesquisa e Desenvolvimento (CNPq) for productivity in research.

\section{REFERENCES}

1. Brasil. Ministério da Saúde. Manual de vigilância e controle da leishmaniose visceral. Brasília: Ministério da Saúde. 2006.

2. Bevilacqua PD, Paixão HH, Modena CM, Castro MC. Urbanização da leishmaniose visceral em Belo Horizonte. Arq Bras Med Vet Zootec. 2001;53:1-8.

3. Carreira JC. Leishmaniasis in domestic dogs: epidemiological aspects. Cad Saude Publica. $2005 ; 21: 324-8$.

4. Gontijo CM, Melo MN. Leishmaniose visceral no Brasil: quadro atual, desafios e perspectivas. Rev Bras Epidemiol. 2004,7:338-49.

5. Grimaldi G Jr, Teva A, Ferreira AL, Santos CB, Pinto I, Azevedo CT, et al. Evaluation of a novel chromatographic immunoassay based on Dual-Path Platform technology (DPP® CVL rapid test) for the serodiagnosis of canine visceral leishmaniasis. Trans R Soc Trop Med Hyg. 2012;106:54-9.

6. Figueiredo FB, Madeira MF, Menezes RC, Pacheco RS, Pires MQ, Furtado MC, et al. Efficacy of an indirect immunofluorescence test in the diagnosis of canine leishmaniosis. Vet J. 2010;186:123-4.

7. Nathan NA, Narayan E, Smith MM, Horn MJ. Cell block cytology. Improved preparation and its efficacy in diagnostic cytology. Am J Clin Pathol. 2000;114:599-606.

8. Paula AA, da Silva AV, Fernandes O, Jansen AM. The use of immunoblot analysis in the diagnosis of canine visceral leishmaniasis in an endemic area of Rio de Janeiro. J Parasitol. 2003;89:832-6.

9. Silva DA, Madeira MF, Abrantes TR, Filho CJ, Figueiredo FB. Assessment of serological tests for the diagnosis of canine visceral leishmaniasis. Vet J. 2013;195: 252-3.

10. Silva DA, Madeira MF, Teixeira AC, de Souza CM, Figueiredo FB. Laboratory tests performed on Leishmania seroreactive dogs euthanized by the leishmaniasis control program. Vet Parasitol. 2011;179:257.

11. Ferrer L, Aisa MJ, Roura X, Portús M. Serological diagnosis and treatment of canine leishmaniasis. Vet Rec. 1995;136:514-6.

12. Alves WA, Bevilacqua PD. Reflexões sobre a qualidade do diagnóstico da leishmaniose visceral canina em inquéritos epidemiológicos: o caso da epidemia de Belo Horizonte, Minas Gerais, Brasil, 1993-1997. Cad Saude Publica. 2004;20:259-65.

13. Chouihi E, Amri F, Bouslimi N, Siala E, Selmi K, Zallaqua N, et al. Les cultures sur milieu NNN dans le diagnostic biologique des leishmanioses. Pathol Biol (Paris). 2009;57:219-24.

14. Quintella LP, Cuzzi T, Madeira MF, Okamoto T, Schubach AO. Immunoperoxidase technique using an anti-Leishmania (L.) chagasi hyperimmune serum in the diagnosis of culture confirmed American tegumentary leishmaniasis. Rev Inst Med Trop Sao Paulo. 2009;51:83-6.

15. Dharan M. Utility of cell block preparation in endometrial aspiration cytology: a report of 4 cases. Acta Cytol. 2010;54:893-7.

16. Nga ME, Lim GL, Barbro N, Chan NH. Successful retrieval of fine-needle aspiration biopsy material from previously stained smears for immunocytochemistry: a novel technique applied to three soft tissue tumors. Mod Pathol. 2005;18:728-32.

17. Figueiredo FB, Barbosa Filho CJ, Schubach EY, Pereira SA, Nascimento LD, Madeira MF. Relato de caso autóctone de leishmaniose visceral canina na zona sul do município do Rio de Janeiro. Rev Soc Bras Med Trop. 2010;43:98-9. 


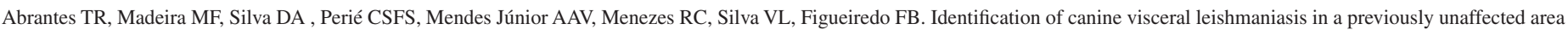
by conventional diagnostic techniques and cell-block fixation. Rev Inst Med Trop Sao Paulo. 2016;58:3.

18. Paula CC, Figueiredo FB, Menezes RC, Mouta-Confort E, Bogio A, Madeira MF. Leishmaniose visceral canina em Marica, Estado do Rio de Janeiro: relato do primeiro caso autóctone. Rev Soc Bras Med Trop. 2009;42:77-8.

19. Cupolillo E, Grimaldi G Jr, Momen H. A general classification of New World Leishmania using numerical zymotaxonomy. Am J Trop Med Hyg.1994;50:296-311.

20. Paltrinieri S, Solano-Gallego L, Fondati A, Lubas G, Gradoni L, Castagnaro M, et al Guidelines for diagnosis and clinical classification of leishmaniasis in dogs. J Am Vet Med Assoc. 2010;236:1184-91.

21. Dinesh DS, Das P, Picado A, Davies A, Speybroeck N, Boelaert M, et al. The efficacy of indoor CDC light traps for collecting the sandfly Phlebotomus argentipes, vector of Leishmania donovani. Med Vet Entomol. 2008;22:120-3.

22. Souza TL, Figueiredo FB, Almeida AB, Benigno CV, Pontes CS, Souza MB. Natural breeding sites of phlebotomine sand flies (Diptera: Psychodidae) on Marambaia Island, Rio de Janeiro State, Brazil. Acta Trop. 2014;136:104-7.

23. Galati, EAB. Classificação de Phlebotominae. In: Rangel EF, Lainson R, editores Flebotomíneos do Brasil. Rio de Janeiro: Fiocruz; 2003.p. 23-51.

24. Brasil. Ministério da Saúde. Secretaria de Vigilância em Saúde. Esclarecimento sobre o diagnóstico sorológico da leishmaniose visceral canina utilizado na rede pública de saúde. Brasília: Ministério da Saúde; 2011. Nota técnica nº 2011.

25. Serra CM, Leal CA, Figueiredo FB, Schubach TM, Duarte R, Uchoa CM, et al. Leishmaniose tegumentar canina em Morada das Aguias (Serra da Tiririca), Marica, Rio de Janeiro, Brasil. Cad Saude Publica. 2003;19:1877-80

26. Liarte DB, Mendonça IL, Luz FC, Abreu EA, Mello GW, Farias TJ, et al. QBC for the diagnosis of human and canine American visceral leishmaniasis: preliminary data. Rev Soc Bras Med Trop. 2001;34:577-81.
27. Tafuri WL, Santos RL, Arantes RM, Gonçalves R, de Melo MN, Michalick MS, et al. An alternative immunohistochemical method for detecting Leishmania amastigotes in paraffin-embedded canine tissues. J Immunol Methods. 2004;292:17-23.

28. Figueiredo FB, Madeira MF, Nascimento LD, Abrantes TR, Mouta-Confort E, Passos SR, et al. Canine visceral leishmaniasis: study of methods for the detection of $\operatorname{IgG}$ in serum and eluate samples. Rev Inst Med Trop Sao Paulo. 2010;52:193-6.

29. Silva AVM, Paula AA, Cabrera MAA, Carreira JC. Leishmaniose em cães domésticos: aspectos epidemiológicos. Cad Saude Publica. 2005;21:324-8.

30. Marzochi MC, Marzochi KB. Leishmanioses em áreas urbanas. Rev Soc Bras Med Trop. 1997;30(Supl 1):162-7.

31. Scalone A, De Luna R, Oliva G, Baldi L, Satta G, Vesco G, et al. Evaluation of the Leishmania recombinant $\mathrm{K} 39$ antigen as a diagnostic marker for canine leishmaniasis and validation of a standardized enzyme-linked immunosorbent assay. Vet Parasitol. 2002; $104: 275-85$

32. Teichmann CE, da Silva AS, Monteiro SG, Barbosa CF, Barcelos R. Evidence of venereal and transplacental transmission of canine visceral leishmaniasis in southern Brazil Acta Sci Vet. 2011;39:1-4

33. Dantas-Torres F. Ticks as vectors of Leishmania parasites. Trends Parasitol. 2011;27: $155-9$

Received: 22 March 2014

Accepted: 18 May 2015 